\title{
Horsenettle (Solanum carolinense) fruit bacterial communities are not variable across fine spatial scales
}

\author{
Ariel R Heminger ${ }^{1,2}$, Lisa K Belden ${ }^{2,3}$, Jacob Barney ${ }^{1,2}$, Brian D Badgley ${ }^{1,2}$, David C Haak ${ }^{\text {Corresp. 1, } 2}$ \\ ${ }^{1}$ School of Plant and Environmental Sciences, Virginia Polytechnic Institute and State University (Virginia Tech), Blacksburg, VA, United States \\ ${ }^{2}$ Global Change Center, Virginia Polytechnic Institute and State University (Virginia Tech), Blacksburg, VA, United States \\ 3 Department of Biological Sciences, Virginia Polytechnic Institute and State University (Virginia Tech), Blacksburg, VA, United States \\ Corresponding Author: David C Haak \\ Email address: dhaak@vt.edu
}

Fruit house microbial communities that are unique from the rest of the plant. While symbiotic microbial communities complete important functions for their hosts, the fruit microbiome is often understudied compared to other plant organs. Fruits are reproductive tissues that house, protect, and facilitate the dispersal of seeds, and thus they are directly tied to plant fitness. Fruit microbial communities may, therefore, also impact plant fitness. In this study, we assessed how bacterial communities associated with fruit of Solanum carolinense, a native herbaceous perennial weed, vary at fine spatial scales $(<0.5 \mathrm{~km})$. A majority of the studies conducted on plant microbial communities have been done at large spatial scales and have observed microbial community variation across these large spatial scales. However, both the environment and pollinators play a role in shaping plant microbial communities and likely have impacts on the plant microbiome at fine scales. We collected fruit samples from nine sampling locations, ranging from 2 to $450 \mathrm{~m}$ apart, and assessed the fruit bacterial communities using 16S rRNA gene amplicon sequencing. Overall, we found no differences in observed richness or microbial community composition among sampling locations. Bacterial community structure of fruits collected near one another were not more different than those that were farther apart at the scales we examined. These fine spatial scales are important to obligate out-crossing plant species such as $S$. carolinense because they are ecologically relevant to pollinators. Thus, our results could imply that pollinators serve to homogenize fruit bacterial communities across these smaller scales. 
1

2 Horsenettle (Solanum carolinense) fruit bacterial communities 3 are not variable across fine spatial scales.

4

5

6 Ariel R. Heminger ${ }^{1,2}$, Lisa K. Belden ${ }^{2,3}$, Jacob Barney ${ }^{1,2}$, Brian D. Badgley ${ }^{1,2}$, David C. Haak ${ }^{1,2}$ 7

$8{ }^{1}$ School of Plant and Environmental Science, Virginia Tech, Blacksburg, VA, USA

$9{ }^{2}$ Global Change Center, Virginia Tech, Blacksburg, VA, USA

$10{ }^{3}$ Department of Biological Sciences, Virginia Tech, Blacksburg, VA, USA

11

12 Corresponding Author:

13 David C. Haak ${ }^{1}$

14

15 Email address: dhaak@vt.edu

16

17 


\section{Abstract}

Fruit house microbial communities are unique from the rest of the plant. While

20 symbiotic microbial communities complete important functions for their hosts, the fruit

21 microbiome is often understudied compared to other plant organs. Fruits are reproductive tissues

22 that house, protect, and facilitate the dispersal of seeds, and thus they are directly tied to plant

23 fitness. Fruit microbial communities may, therefore, also impact plant fitness. In this study, we

24 assessed how bacterial communities associated with fruit of Solanum carolinense, a native

25 herbaceous perennial weed, vary at fine spatial scales $(<0.5 \mathrm{~km})$. A majority of the studies

26 conducted on plant microbial communities have been done at large spatial scales and have

27 observed microbial community variation across these large spatial scales. However, both the

28 environment and pollinators play a role in shaping plant microbial communities and likely have

29 impacts on the plant microbiome at fine scales. We collected fruit samples from nine sampling

30 locations, ranging from 2 to $450 \mathrm{~m}$ apart, and assessed the fruit bacterial communities using $16 \mathrm{~S}$

31 rRNA gene amplicon sequencing. Overall, we found no differences in observed richness or

32 microbial community composition among sampling locations. Bacterial community structure of

33 fruits collected near one another were not more different than those that were farther apart at the

34 scales we examined. These fine spatial scales are important to obligate out-crossing plant species

35 such as $S$. carolinense because they are ecologically relevant to pollinators. Thus, our results

36 could imply that pollinators serve to homogenize fruit bacterial communities across these smaller

37 scales.

\section{Introduction}

Plants, like other organisms, host diverse communities of microorganisms that are

41 typically dominated by bacteria (Stone et al., 2018). Bacteria associated with above-ground

42 portions of plants (the phyllosphere) play an important role in host development and health 
43 (Gibbons \& Gilbert, 2015; Grover et al., 2011; Richardson et al., 2009; Selosse et al., 2004).

44 Thus, understanding how these bacterial communities are formed and the factors that shape

45 changes in these communities can lead to important insights about plant health. This is especially

46 true when we consider tissues like fruits, which are directly tied to plant fitness (Compant et al.,

47 2011; Eck et al., 2019; Nelson, 2018; Tewksbury et al., 2008). Despite this importance, few

48 studies have examined patterns of bacterial community diversity among fruits (Compant et al.,

49 2011; Miura et al., 2017).

A first step in understanding what shapes plant-associated microbial communities is

51 characterizing variation over time and space. The tendency for communities to become

52 increasingly dissimilar with distance is often referred to as "distance decay" (Finkel et al., 2012;

53 Morrison-Whittle \& Goddard, 2015; Peay et al., 2010), which have been observed in microbial

54 communities (Feng et al., 2019). Viewed through an evolutionary lens, this pattern of community

55 turnover could arise from two distinct mechanisms: local adaptation and dispersal limitation

56 (Bell, 2010). In the first case, communities change concordantly with niche turnover along an

57 abiotic or biotic gradient. In the latter case, community change occurs in the absence of an

58 underlying environmental or resource gradient, exhibiting geographical patterns (Barreto et al.,

59 2014). Studies of phyllosphere microbes have found mixed evidence for these mechanisms. For

60 instance, a recent study of Tamarix leaves found that bacterial community structure was

61 influenced by both geographic distance and environmental heterogeneity (Finkel et al., 2012).

62 Yet, it is challenging to find generalizable patterns, as most studies of phyllosphere communities

63 focus on leaves over large spatial scales, maximizing the potential to detect community

64 differences, even though not all studies find evidence of distance decay. For example, a study of

65 Pinus spp. at distances ranging from 1,800-2,400 km found no evidence that microbial 
66 communities became more distinct with increasing distance (Redford et al., 2010). In contrast, a

67 recent study of Magnolia grandiflora leaves at distances up to $452 \mathrm{~m}$ found that microbial

68 communities did become more distinct the further away they were (Stone \& Jackson, 2016).

69 While widespread, bacteria may not be evenly distributed over large spatial scales

70 (Bahram et al., 2018; Delgado-Baquerizo et al., 2018). Microbial communities on plants can be

71 regulated by local biotic and abiotic conditions, including plant host species, geographic

72 location, light, temperature, wind, and humidity (Berg et al., 2014; De Vries et al., 2012). In

73 addition, the factors that shape bacterial distribution at global scales, such as soil $\mathrm{pH}$ and

74 temperature (Bahram et al., 2018; Delgado-Baquerizo et al., 2018), may be more nuanced or

75 attenuated at local levels (Igwe \& Vannette, 2019; Storey et al., 2018). Further, the factors

76 shaping microbial diversity may interact across scales to influence community assembly within

77 particular communities, e.g., rhizosphere versus leaves (Levin, 1992). For example, using genetic

78 mutants, Lebeis et al., (2012) demonstrated that Arabidopsis plants are capable of structuring soil

79 bacterial communities. In contrast, Ottesen et al. (2016) found that in the tomato phyllosphere

80 when host and other biotic factors were ruled out using plastic plants, bacterial communities

81 were similar between the plastic plants and normal controls.

82 Studies at finer spatial scales are more limited (Stone \& Jackson, 2016), and even fewer

83 studies have been conducted in fruit microbial communities (Miura et al., 2017). Fruit microbial

84 communities are likely shaped by a combination of biotic and abiotic factors similar to those that

85 shape the leaf microbial communities. Yet, recent studies have also shown that fruit and flower

86 microbial communities differ from other above ground plant tissues (Ottesen et al., 2013;

87 Rasmann et al., 2012; Shade et al., 2013). One possible explanation for this is that these tissues

88 interface directly with pollinators, biotic sources of additional microbes (Russell et al., 2019), 
89 especially in obligate outcrossing species (Wei \& Ashman, 2018). Since pollinators transfer

90 microbes from one flower to the next (Ushio et al., 2015), they may contribute to homogenizing

91 microbial communities locally at these finer spatial scales.

92 Fruit and flowers are especially warranted to studies at finer spatial scales, as pollinator

93 interactions are most likely to impact these tissues (Rebolleda-Gómez et al., 2019; Ushio et al.,

94 2015; Zemenick et al., 2021). Recent studies found that plant communities with a similar floral

95 visitor community have similar microbes (Rebolleda Gómez \& Ashman, 2019; Zemenick et al.,

96 2019). However, they found that while flowers were hubs for arthropod visitation, flowers did

97 not necessarily serve as hubs for microbes, which suggests a degree of host sorting (Zemenick et

98 al., 2021) which supports the idea that floral visitors shape microbial communities. However,

99 little is known regarding how this could impact fruit microbial communities.

100 Here, we hypothesized that bacterial communities associated with fruit that are spatially

101 closer to one another will be more similar. This is because they are more likely to share a similar

102 environment and be exposed to the same pollinator, since pollinators are known to visit multiple

103 flowers. To address this hypothesis, we sampled the fruit of Carolina horsenettle, Solanum

104 carolinense, a native herbaceous perennial weed that is an obligate outcrossing species, at a fine

105 scale (under 450 meters) and compared bacterial community composition at different distances

106 to determine if we observed distance decay in the bacterial communities associated with fruit.

107 Materials \& Methods

108

109

Study species: Solanum carolinense.

110 Solanum carolinense L. (Solanaceae) is a native herbaceous perennial weed found

111 throughout most of the eastern United States. This species reproduces both via underground

112 horizontal roots (rhizomes) and by seed. Inflorescences are in clusters of 1-12 blossoms and are 
113 frequently perfect and functionally hermaphroditic. Solanum carolinense is known to be an

114 obligate out-crosser, meaning that it cannot self-pollinate and relies on pollinators, specifically

115 buzz pollinators, for fertilization (Hardin et al., 1972). Bombus impatiens, the eastern bumblebee,

116 is a common pollinator of $S$. carolinense in the eastern United States. Fruits of $S$. carolinense are

117 yellow to orange in color and $1-2.5 \mathrm{~cm}$ in diameter, and the reproductive season for $S$.

118 carolinense is from late summer until the first frost (Basset \& Munro, 1986). S. carolinense was

119 chosen for this study because it grows in a variety of habitats and can be found at relatively high

120 abundances locally. S. carolinense is closely related to Solanum lycopersicum, so this work could

121 indirectly provide insights into bacterial community similarities in commercially important

122 Solanum species.

123

124 Sampling, processing, and DNA extraction.

125 A total of 23 fruit samples, from nine different sampling locations of $S$. carolinense, were 126 collected from around Blacksburg, VA, USA on November 15 $5^{\text {th }}, 2017$ (Fig. 1, Supplemental

127 Table 1). The use of the site was approved by the Department of Parks and Recreation of the

128 town of Blacksburg. Sample locations ranged in distance from 2 to 450 meters apart, and the

129 total number of individual plants sampled ranged from 2 to 5 individuals/site. Since, $S$.

130 carolinense is a perennial species that can spread via underground rhizomes generating clusters

131 of clonal plants it is possible that multiple of $S$. carolinense in a collection site are genetically

132 identical. One fruit sample per $S$. carolinense ramet was collected aseptically in $50 \mathrm{ml}$ falcon

133 tubes and stored at $-80^{\circ} \mathrm{C}$ until DNA extraction. Prior to DNA extraction, samples were sliced

134 using EtOH flame sterilized forceps and scalpels so that the sample included both surface and 
135 internal microbes. The samples were then disrupted with beads. DNA was extracted from

136 samples using the DNeasy PowerSoil ${ }^{\circledR}$ Kit (Qiagen USA catalog no. 12888-100).

138 Library preparation.

139 LNA PCR.

$140 \quad$ Mitochondria and chloroplast from plant tissues pose a challenge when investigating

141 plant microbial communities, as they share an evolutionary history with bacteria and contain $16 \mathrm{~S}$

142 rRNA genes (Sakai \& Ikenaga, 2013). Thus, many of the primers used to analyze bacterial

143 community structure will also bind and amplify mitochondria and chloroplast DNA (Ghyselinck

144 et al., 2013). To reduce the amount of mitochondrial and chloroplast amplification in our

145 samples, we used an initial locked nucleic acid (LNA) PCR with the primers 63f-mod and 1492r

146 (Ikenaga et al., 2016; Yu et al., 2016). The LNA mixture contained: $12.5 \mu \mathrm{L}$ Premix Hot Start

147 Accustart II Supermix, $1.0 \mu \mathrm{L}$ 63f-mod primer $(20 \mathrm{pmol} / \mu \mathrm{L}), 1.0 \mu \mathrm{L} 1492 \mathrm{r}(20 \mathrm{pmol} / \mu \mathrm{L}), 2.0$

$148 \mu \mathrm{L}$ LNA-Mit63 (20 pmol/ $\mu \mathrm{L}), 2.0 \mu \mathrm{L}$ LNA-Mit1492 $(20 \mathrm{pmol} / \mu \mathrm{L}), 2.0 \mu \mathrm{L}$ LNA-Pla63c $(20$

$149 \mathrm{pmol} / \mu \mathrm{L}), 2.0 \mathrm{LNA}-\mathrm{Pla} 1492 \mathrm{~b}(20 \mathrm{pmol} / \mu \mathrm{L}), 1.5 \mu \mathrm{L}$ sterile water, and $1.0 \mu \mathrm{L}$ of DNA template

150 (Supplemental Table 2). LNA PCR was performed in sets of eight, which consisted of seven

151 samples and one negative control without DNA template per run. The amplification conditions

152 were $94^{\circ} \mathrm{C}$ for 1 minute to denature the DNA, followed by 30 cycles of $94^{\circ} \mathrm{C}$ for 1 minute, $70^{\circ} \mathrm{C}$

153 for 1 minute to anneal the LNA oligonucleotides, $54^{\circ} \mathrm{C}$ for 1 minute to anneal primers, and $72^{\circ} \mathrm{C}$

154 for 2 minutes, and a final extension step of $72^{\circ} \mathrm{C}$ for 10 minutes. PCR products and negative

155 controls were visualized using a 1.5\% agarose gel to ensure that samples had amplified correctly. 156

157 Illumina 16S PCR. 

individually barcoded 806R, with the LNA product as the template. PCR was run in duplicate

160 (two $25 \mu \mathrm{L}$ reactions) along with a negative control that did not contain any template DNA. The

161 PCR mixture contained: $12 \mu \mathrm{L}$ UltraClean PCR grade H2O, $10 \mu \mathrm{L}$ of 5 Prime Hot Master Mix,

$1620.5 \mu \mathrm{L}$ of forward primer $515 \mathrm{f}$ and $0.5 \mathrm{ul}$ of reverse primer $806 \mathrm{R}$ (barcoded), and $2 \mu \mathrm{L}$ of

163 template DNA (Supplemental Table 2). The amplification conditions were: $94^{\circ} \mathrm{C}$ for 3 minutes

164 for the initial denaturation, followed by 30 cycles of $94^{\circ} \mathrm{C}$ for 45 seconds, $50^{\circ} \mathrm{C}$ for 1 minute, and

$16572^{\circ} \mathrm{C}$ for 90 seconds, and a final extension of $72^{\circ} \mathrm{C}$ for 10 minutes. Following PCR, the duplicate

166 samples were combined and were run on an $1.5 \%$ agarose gel to ensure that samples had

167 amplified correctly. Concentrations for the samples were recorded using a Qubit Fluorometer 2.0

168 with the HS DNA kit. Equimolar amounts of each sample were then pooled and cleaned using

169 the Qiaquick PCR purification kit. Amplicon sequencing was completed at the Dana Farber

170 Cancer Institute at Harvard University using 250bp single end reads on the Illumina Mi-Seq.

171

172 Identifying ASVs.

173 Demultiplexed raw reads were processed in the R computing environment (R Core Team

174 2020). The package manager Bioconductor (Callahan et al., 2016) was used to implement

175 packages, including DADA2 1.12.1 (Callahan et al., 2016), ggplot2 3.2.1 (Wickham, 2015),

176 DESeq2 1.24.0 (Love et al., 2014), phyloseq 1.28.0 (Mcmurdie \& Holmes, n.d.), and vegan 2.5-6

177 (Oksanen et al., 2019). Raw reads were quality processed using methods laid out in the DADA2

178 tutorial (Callahan et al., 2016). The reads were first visualized using the "plotQualityProfile"

179 function in DADA2, which allowed us to monitor for low quality reads. No trimming was

180 necessary, so we maintained the full $250 \mathrm{bp}$ of the reads for analyses. The "learnErrors" function 
181 was then used to evaluate the error rate of the data set. The "derepFastq" function was used to

182 combine identical sequences into unique sequences, and from this a table of amplicon sequence

183 variants (ASVs) was generated using the "makeSequenceTable" function.

184 Chimeric reads were removed using the "removeBimeraDenovo" function, which

185 identified 1700 chimeras out of 4225 input ASVs (Supplemental Table 3). Taxonomy was

186 assigned to the remaining ASVs using the "assignTaxonomy" function in DADA2 and the

187 SILVA v123 database (Quast et al., 2013). Samples that could not be assigned to bacterial phyla

188 were removed, which resulted in a total of 15 phyla remaining. Any mitochondria or chloroplast

189 reads that persisted, along with unclassified reads, were also removed. After processing and

190 quality control, our dataset consisted of 1874 ASVs across all 23 samples. From this final ASV

191 set, phyla with read counts $<10$ were removed (McMurdie and Holmes n.d.). After this step, our

192 dataset consisted of 1846 ASVs across all 23 samples including the following phyla:

193 Acidobacteria, Actinobacteria, Armatiomonadetes, Bacteroidetes, Firmicutes, and

194 Proteobacteria.

195

196 Richness and beta diversity.

197 Comparisons of ASVs among each sampling location were conducted using observed

198 richness and Shannon alpha diversity indices using the "plot_richness" function and visualized

199 using phyloseq in R. Observed richness indicates the number of ASVs and provides information

200 on the number of ASVs that are found within each sample per site. Shannon's diversity index

201 considers both ASV richness and evenness. Faith's phylogenetic diversity was calculated using

202 the "estimate_pd" function in btools (Battaglia 2021). A Kruskal-Wallis rank sum test was used 
203 on both observed richness and Faith's phylogenetic diversity to analyze differences between each 204 of the sites.

205 To assess differences in bacterial community composition among locations, we compared

206 beta diversity using two distance metrics: Bray-Curtis dissimilarity and Jaccard index. Bray-

207 Curtis dissimilarity is based on ASV relative abundance, while Jaccard is based only on

208 presence/absence of ASVs. Differences in Bray-Curtis dissimilarity and Jaccard were analyzed

209 using PERMANOVA and were visualized using PCoA plots.

210 To test for spatial patterns of dissimilarity among locations, we conducted a Mantel test

211 to estimate the correlation between two matrices. We chose to use the Mantel test because it

212 allows us to compare spatial relationships with bacterial community composition and is

213 commonly used in ecology. We used the Mantel test to look for correlations between the Bray-

214 Curtis dissimilarity matrix and the spatial distance matrix among all 23 samples, where samples

215 within each site were considered to have a distance of $0 \mathrm{~m}$. Pearson's product-moment

216 correlation was used to test for differences. One of the assumptions of PERMANOVA is that

217 sample size is equal with similar dispersion between samples. Since we knew that we had uneven

218 sampling we tested the heterogeneous variance among microbial communities. This was tested

219 using the function "betadisper", which is a multivariate analog of Levene's test for homogeneity 220 of variances.

221 To look for core bacterial communities, we assessed which ASVs were most prevalent 222 and their relative abundances. We conducted this using the "core_members" function from the 223 microbiome package (Lahti et al. 2017). We set our parameters such that ASVs needed to be 224 present in at least $60 \%$ of the samples and had a relative abundance of at least $0.10 \%$. 225 226

\section{Results}


228 from each sampling location, we estimated relative abundances of different bacterial orders (Fig.

229 2). The orders Enterobacteriales, Sphingomonadales, Sphingobacteriales, Rhizobiales,

230 Cytophagales, and Micrococcales were found to make up the greatest proportion of the relative

231 abundance found at each sampling site (Fig. 2). Interestingly, some differences in abundance

232 were found across sites. The orders Micrococcales, Caulobacterales, and Betaproteobacteriales

233 were present in some sites and not found at others. Micrococcales was found at sites 2, 4, and 5,

234 and Caulobacterales was found at sites 2, 5, and 7. Both Micrococcales and Caulobacterales were

235 found at relatively low abundances compared to other prominent taxa. Betaproteobacteriales was

236 found at relatively low abundances at all the sites except site 1. Flavobacteriales was also found

237 at relatively low abundance but found at all the sites sampled. The most common bacterial

238 genera by relative abundance were: Aureimonas, Chryseobacterium, Dyadobacter,

239 Hymenobacter, Methlobacterium, Mucilaginibacter, Neorhizobium, Pantoea, Pedobacter,

240 Pseudomonas, Rosenbergiella, Sphingomonas, Spirosoma, and Tatumella; these all had a

241 relative abundance of $\geq 0.1 \%$.

242

243 Bacterial community analysis.

244 Shannon diversity, observed richness, and Faith's phylogenetic diversity were then

245 calculated for each sample location using abundance data to determine richness and evenness

246 (Fig. 3). Although there was some separation of mean values in alpha diversity across sites, none

247 of these differences were significant for observed richness $(p=0.2173, \mathrm{DF}=7$, chi-squared $=$

248 9.5226) or Faith's phylogenetic diversity via Kruskal-Wallis rank sum test $(p=0.1879, \mathrm{DF}=7$,

249 chi-squared $=10.012$ ). The high values observed in mean alpha diversity likely result from high

250 variation within sites (Fig. 1). 
252 in bacterial community structure across sampling locations (PERMANOVA, $p=0.711, \mathrm{DF}=22$,

$\left.253 \mathrm{R}^{2}=0.3033\right)$. PCoA analysis revealed that the first two components of variation explained a

254 combined $29.1 \%$ (18.3\% and $10.8 \%$ respectively) of the variation in bacterial community

255 composition, however we did not find any significant clustering of samples by site (Fig. 4). For

256 example, samples from the same location (color in Fig. 4) tended to be dispersed across the axes

257 of variation. Likewise, no differences in bacterial community composition among sampling

258 locations was identified using the Jaccard index (Supplemental Fig. 1, PERMANOVA, $p=$

$\left.2590.688, \mathrm{R}^{2}=0.30896\right)$. These findings were supported by a Mantel test of Bray-Curtis dissimilarity

260 index and calculated spatial distances that failed to detect a relationship between bacterial

261 diversity and distance (Fig. 5 Pearson's, Mantel statistic r: 0.03343, $p=0.302, \mathrm{DF}=22$ ).

262 Together, these results suggest that fruit bacterial diversity is not differentiated at this spatial 263 scale.

To investigate the proportion of shared taxa among samples from all sites, we conducted an analysis of the core microbial community and found that just 25 ASVs were present in at least $60 \%$ of the samples with a relative abundance $>0.10 \%$ (Fig. 6 ). The top five taxa that dominated the core microbial communities, as determined by a relative abundance of $>1.0 \%$ and prevalence $>50 \%$ were Aureimonas spp., Pantoea spp., Sphingomonas spp., Hymenobacter spp., and Pedobacter spp. Thus, $0.0135 \%$ of ASVs we identified in our analysis were found in the majority of fruit and less than half of these were found with a relative abundance $>0.30 \%$.

271 Finally, we found that Aureimonas spp. persisted with a very high prevalence $>90 \%$ at relative 272 abundance levels up to $1.0 \%$. 


\section{Discussion}

275 The advent of non-culture based microbial community profiling has led to a wealth of

276 information about patterns and scales of community diversity among bacteria that form close

277 associations with plant organs (Compant et al., 2011; Junker et al., 2011; Ottesen et al., 2016;

278 Shade et al., 2013). Non-pathogenic fruit-associated bacteria have received less attention, yet

279 these communities have important implications for host fitness. This study provides a first

280 glimpse into the composition of fruit bacterial communities of $S$. carolinense. This study also is

281 the first to explore patterns of bacterial community structure of fruit in natural populations at fine

282 spatial scales. This is one of the first studies to be conducted in fruit at such a fine spatial scale.

283 We found that bacterial community richness and diversity are similar at distances up to $450 \mathrm{~m}$,

284 and there is no correlation between community structure and distance, suggesting no evidence of

285 distance-decay at these fine spatial scales. Factors such as microenvironment or biotic

286 interactions (pollinators, seed predators, etc.) may, therefore, be more important for shaping

287 patterns of bacterial diversity among fruit. It is also possible that a lack of genetic diversity

288 among host plants (S. carolinense can and does reproduce clonally through rhizomes) could

289 account for a lack of distance decay. However, because rhizome growth is generally limited to

290 about $1.25 \mathrm{~m}$ (Kiltz 1930) from the ramet, we would expect to reduce variation at the site level

291 (Imaizumi et al., 2006), which was not apparent in this study. Still, the role of host-genotype

292 level filtering in shaping fruit microbial communities in this system remains an open question.

293 As with other studies, we found that fruits are colonized by a diverse array of bacteria. In

294 our study, we found that the Enterobacteriales, Rhizobiales, and Cytophagales orders comprised

295 about $63 \%$ of the relative abundance across all samples. Within these orders, the most frequently

296 identified genera were Pantoea, Aurantimonas, and Methylobacterium. In other plant hosts, 
297 different genera seem to dominate. For instance, fruits of congeneric tomatoes (Solanum

298 lycopersicum) are dominated by the genera Xanthomonas, Rhizobium, and Pseudomonas

299 (Ottesen et al., 2013); the only overlapping genus identified in our study was Sphingomonas.

300 These findings reinforce the importance of host species (Igwe \& Vannette, 2019; Knief et al.,

301 2010; Ottesen et al., 2016; Wei \& Ashman, 2018) and environment (Knief et al., 2010) in

302 shaping bacterial communities in fruit. Despite the substantial variation in diversity, we

303 identified 25 ASVs that were present in a majority of samples (> 60\%) (Fig 6). Subsetting these

304 further we identified five taxa that were present in nearly every sample with a relative abundance

$305>0.10 \%$, Aureimonas spp., Pantoea spp, Sphingomonas spp., Hymenobacter spp., and

306 Pedobacter spp. These top five taxa have all previously been reported from different plant tissue

307 samples. Aureimonas spp. have been identified in the phyllosphere of Galium album (Aydogan

308 et al., 2016), the bark of Populus spp. (Li et al., 2018), and, recently in Actinidia deliciosa (Ares

309 et al., 2021). Pantoea spp. have been identified as endophytes in the stems of tomatoes, Solanum

310 lycopersicum (Dong et al., 2019). Pantoea spp. can also cause internal fruit rot in Cucurbitaceae

311 (Kido et al., 2008). Sphingomonas spp. have been found in tomato specifically on the lower

312 stems and leaves (Ottesen et al., 2013), can cause disease in Cucurbitaceae (Buonaurio et al.,

313 2001), and can be endophytes that produce gibberellins (Latif Khan et al., 2014). Hymenbobacter

314 spp. have been observed on Hedera spp. (Smets et al., 2016) and in the phyllosphere of Galium

315 album (Aydogan et al., 2016). Pedobacter spp. have been observed in the phyllosphere of

316 Solanum tuberosum, which is closely related to our study species (Manter et al., 2010), as well as

317 the leaves of Arabidopsis thaliana (Qi et al., 2021).

318 Comparing bacterial community diversity, we found a great deal of variation within and

319 among sites (Fig. 3 and Fig. 4). This variation was not partitioned by site or distance (Fig. 5) and 
320 is consistent with diverse source pools and environmental filtering (Rebolleda Gómez \&

321 Ashman, 2019). It is important, however, to consider these findings with the caveat that reduced

322 sample sizes negatively impact alpha diversity statistics (Willis, 2019). Thus, while widespread,

323 bacterial taxa may not be evenly distributed over large spatial scales (Bahram et al., 2018;

324 Delgado-Baquerizo et al., 2018).

325 Environment is an important source and factor shaping leaf microbial communities across

326 fine spatial scales. This has been observed by Stone and Jackson (2016) found that bacterial

327 communities associated with the leaves of Magnolia grandiflora exhibited a distance-decay

328 relationship across a similar distance to the present study $(1-452 \mathrm{~m})$. Ultimately, Stone and

329 Jackson (2016) conclude that subtle differences in environmental conditions contributed to

330 differences in microbial communities. The lack of distance-decay in the present study may be for

331 several reasons. Our sampling may not have covered a sufficient range nor elevation (17 $\mathrm{m})$ in

332 environmental variation however we did have variation in slope and aspect (north and west

333 facing) (Fig. 1).

334 Host species and genotype may also play a role in shaping microbial communities

335 associated with the plant (Laforest-Lapointe et al., 2016; Redford et al., 2010). However, there

336 has been contrasting evidence in Solanum lycopersicum leaves, suggesting that the host plant is

337 not different from a controlled plastic plant (Ottesen et al. 2016). In addition, plant organs may

338 also play a role in the interactions shaping distance decay. Several studies have documented

339 distinct microbial communities across plant tissues (Compant et al., 2011; Junker \& Keller,

340 2015; Ottesen et al., 2013; Shade et al., 2013), including different tissues within the same organ

341 (Hayes et al., 2021). This also means that microbial communities associated with particular plant

342 organs may have a different set of organizing rules (Rebolleda Gómez \& Ashman, 2019; Wei \& 
343 Ashman, 2018; Zheng \& Gong, 2019). For instance, flowers and fruits that rely on pollinators,

344 which spread microbes, may not display distance decay at finer spatial scales. Another important

345 consideration is the production of secondary compounds within the fruit. As with other members

346 of the Solanaceae S. carolinense fruit contain steroidal glycoalkaloids that likely impact

347 microbial communities (Milner et al., 2011). Future studies can determine the relative impact of

348 SGAs on microbial communities by isolating the endophytic component of fruit microbial

349 communities. By understanding how and when microbial communities are shaped in fruits and

350 flowers we can learn how this impacts host fitness (Baltrus, 2020; Taylor et al., 2014).

351 Dispersal is another important component acting across these smaller spatial scales. For

352 instance, Miura et al. (2017) investigated leaves and fruits in vineyards in Chile that were within

$35335 \mathrm{~km}$ of one another and found that at spatial scales $<2 \mathrm{~km}$ fungal community dissimilarity

354 increased with distance; however, the bacterial communities did not show similar patterns. This

355 may be because fungal spores tend to have more limited dispersal than bacteria (Peay \& Bruns,

356 2014). However, over large distances (1,800-2,400 km) Pinus spp. leaves showed no variation

357 with an increase in distance (Redford et al. 2010), yet there was a distance-decay effect observed

358 in Tamarix spp. (Finkel et a. 2012). We are still in the early phases of understanding how

359 microbial communities are shaped across the landscape, particularly in reproductive tissues.

360 Biotic interactions can drive facilitated bacterial dispersal (Russell et al., 2019). As an obligate

361 outcrossing species, S. carolinense depends on pollinators. Pollinators leave microbial footprints

362 on the flowers that they visit (Ushio et al., 2015), which may influence floral microbial

363 communities, and possibly fruit microbial communities. Thus, the observed similarities among

364 bacterial communities in our study could result from pollinator transmission, though we do not

365 yet know if bacterial communities are transferred from flowers to fruit in this system. In 
366 addition to pollinators, seed feeding insects, such as the Lygaeidae, pierce fruit and feed on the

367 developing seeds. This process introduces microbes to fruits (Tewksbury et al., 2008) and may

368 be another source of bacterial dispersal. Indeed, our clustering analysis identified some axes of

369 separation for samples within a site, which could be indicative of these sorts of biotic filters, yet

370 more work needs to be done to test this hypothesis.

371

372 Conclusions

373

374

In our study, we found that richness, diversity, and community structure of bacterial

375

376

377

378

379

380

381

382

383

384

385

386

387

388

389 390 communities associated with the fruit of $S$. carolinense are similar at fine spatial scales, suggesting there is no evidence of a distance-decay relationship. Thus, we are left with the question at what point do bacterial communities become distinct in the fruit of Solanum carolinense? In order to address this question, samples will need to be taken at larger spatial scales to determine when these communities become distinct. We also know that environment, pollinator, and host species play a large role in shaping microbial communities (Igwe \& Vannette, 2019; Knief et al., 2010; Ottesen et al., 2016; Ushio et al., 2015; Wei \& Ashman, 2018), but the degree to which these factors shape the bacterial communities found in Solanum carolinense fruit remains unclear. To address this, sampling over a large spatial scale should be done across a variety of environmental conditions. From that sampling, a comparison of similar environments, microbial communities will help to address the degree that environment plays a role in shaping microbial communities and determine if spatial scale plays a larger role than environment. To address the role of host species in shaping microbial communities, research should be conducted to compare the genotype of host species within a site to determine if in fact hosts that are closer related are more similar with regards to their microbial communities. 


\section{Acknowledgements}

392

393 We would like to thank the town of Blacksburg for allowing us to use Heritage Park as a field

394 site for this study. We would also like to thank Andie Gonzales and Rafael Castañeda-Saldaña

395 for helping with the field collections and Angie Estrada for helping with the LNA and Illumina 396 PCR.

397

398

\section{Data Availability}

399 The code used to generate this data can be found at VTech Works at

$400 \mathrm{https}: / /$ figshare.com/s/ffea66d1ae2bb667d509 the metadata can be found at VTech Works at

$401 \mathrm{https} / /$ figshare.com/s/9aa50f33b0ce60a63934 and the sequences can be found at

402

403

404

405

406

407

408

409

410

411

412

https://www.ncbi.nlm.nih.gov/Traces/study/?acc=PRJNA735185.

\section{References}

Ares, A., Pereira, J., Garcia, E., Costa, J., \& Tiago, I. (2021). The leaf bacterial microbiota of female and male kiwifruit plants in distinct seasons: assessing the impact of Pseudomonas syringae pv. actinidiae. Phytobiomes Journal, PBIOMES-09-20-0070-R. https://doi.org/10.1094/PBIOMES-09-20-0070-R

Aydogan, E. L., Busse, H. J., Moser, G., Müller, C., Kämpfer, P., \& Glaeser, S. P. (2016). Aureimonas galii sp. nov. and Aureimonas pseudogalii sp. nov. isolated from the phyllosphere of Galium album. International Journal of Systematic and Evolutionary 
414 Bahram, M., Hildebrand, F., Forslund, S. K., Anderson, J. L., Soudzilovskaia, N. A., Bodegom,

415 P. M., Bengtsson-Palme, J., Anslan, S., Coelho, L. P., Harend, H., Huerta-Cepas, J.,

416 Medema, M. H., Maltz, M. R., Mundra, S., Olsson, P. A., Pent, M., Põlme, S., Sunagawa,

417 S., Ryberg, M., Bork, P. (2018). Structure and function of the global topsoil microbiome.

418 Nature, 560(7717), 233-237. https://doi.org/10.1038/s41586-018-0386-6

419 Baltrus, D. A. (2020). Bacterial dispersal and biogeography as underappreciated influences on 420 phytobiomes. In Current Opinion in Plant Biology (Vol. 56, pp. 37-46). Elsevier Ltd.

$421 \quad$ https://doi.org/10.1016/j.pbi.2020.02.010

422 Barreto, D. P., Conrad, R., Klose, M., Claus, P., \& Enrich-Prast, A. (2014). Distance-Decay and 423 Taxa-Area Relationships for Bacteria, Archaea and Methanogenic Archaea in a Tropical 424 Lake Sediment. PLoS ONE, 9(10), e110128. https://doi.org/10.1371/journal.pone.0110128

425 Bassett, I. J., \& Munro, D. B. (1986). The Biology of Canadian weeds.: 78. Solanum carolinense 426 L. and Solanum rostratum Dunal. Canadian Journal of Plant Science, 66(4), 977-991. https://doi.org/10.4141/cjps86-120

428

429

430

431

432 433

434

435

Bell, T. (2010). Experimental tests of the bacterial distance-decay relationship. ISME Journal, 4(11), 1357-1365. https://doi.org/10.1038/ismej.2010.77

Berg, G., Grube, M., Schloter, M., \& Smalla, K. (2014). Unraveling the plant microbiome: Looking back and future perspectives. In Frontiers in Microbiology (Vol. 5, Issue JUN, p. 148). Frontiers Research Foundation. https://doi.org/10.3389/fmicb.2014.00148

Buonaurio, R., Stravato, V. M., \& Cappelli, C. (2001). Brown spot caused by Sphingomonas sp. on yellow Spanish melon fruits in Spain. Plant Pathology, 50(3), 397-401. https://doi.org/10.1046/j.1365-3059.2001.00571.x 
436 Callahan, B. J., Sankaran, K., Fukuyama, J. A., McMurdie, P. J., \& Holmes, S. P. (2016).

437 Bioconductor Workflow for Microbiome Data Analysis: from raw reads to community

438 analyses. F1000Research, 5, 1492. https://doi.org/10.12688/f1000research.8986.2

439 Compant, S., Mitter, B., Colli-Mull, J. G., Gangl, H., \& Sessitsch, A. (2011). Endophytes of

440 Grapevine Flowers, Berries, and Seeds: Identification of Cultivable Bacteria, Comparison

441 with Other Plant Parts, and Visualization of Niches of Colonization. Microbial Ecology,

442 62(1), 188-197. https://doi.org/10.1007/s00248-011-9883-y

443 De Vries, F. T., Liiri, M. E., Bjørnlund, L., Bowker, M. A., Christensen, S., Setälä, H. M., \&

444 Bardgett, R. D. (2012). Land use alters the resistance and resilience of soil food webs to 445 drought. Nature Climate Change, 2(4), 276-280. https://doi.org/10.1038/nclimate1368

446 Delgado-Baquerizo, M., Oliverio, A. M., Brewer, T. E., Benavent-González, A., Eldridge, D. J., 447 Bardgett, R. D., Maestre, F. T., Singh, B. K., \& Fierer, N. (2018). A global atlas of the 448 dominant bacteria found in soil. Science, 359(6373), 320-325. https://doi.org/10.1126/science.aap9516

450 Dong, C.-J., Wang, L.-L., Li, Q., \& Shang, Q.-M. (2019). Bacterial communities in the 451 rhizosphere, phyllosphere and endosphere of tomato plants. PLOS ONE, 14(11), e0223847. https://doi.org/10.1371/journal.pone.0223847

453 Eck, J. L., Stump, S. M., Delavaux, C. S., Mangan, S. A., \& Comita, L. S. (2019). Evidence of 454 within-species specialization by soil microbes and the implications for plant community 455 diversity. Proceedings of the National Academy of Sciences of the United States of America,

457 Feng, M., Tripathi, B. M., Shi, Y., Adams, J. M., Zhu, Y., \& Chu, H. (2019). Interpreting

458 distance-decay pattern of soil bacteria via quantifying the assembly processes at multiple 
spatial scales. MicrobiologyOpen, 8(9), e00851. https://doi.org/10.1002/mbo3.851

460 Finkel, O. M., Burch, A. Y., Elad, T., Huse, S. M., Lindow, S. E., Post, A. F., \& Belkin, S.

461 (2012). Distance-decay relationships partially determine diversity patterns of phyllosphere

462 bacteria on Tamrix trees across the sonoran desert. Applied and Environmental

463 Microbiology, 78(17), 6187-6193. https://doi.org/10.1128/AEM.00888-12

464 Ghyselinck, J., Pfeiffer, S., Heylen, K., Sessitsch, A., \& De Vos, P. (2013). The effect of primer

465 choice and short read sequences on the outcome of 16S rRNA gene based diversity studies.

$466 \quad$ PloS One, 8(8). https://doi.org/10.1371/journal.pone.0071360

467 Gibbons, S. M., \& Gilbert, J. A. (2015). Microbial diversity-exploration of natural ecosystems

468 and microbiomes. In Current Opinion in Genetics and Development (Vol. 35, pp. 66-72).

$469 \quad$ Elsevier Ltd. https://doi.org/10.1016/j.gde.2015.10.003

470 Grover, M., Ali, S. Z., Sandhya, V., Rasul, A., \& Venkateswarlu, B. (2011). Role of

471 microorganisms in adaptation of agriculture crops to abiotic stresses. World Journal of

472 Microbiology and Biotechnology, 27(5), 1231-1240. https://doi.org/10.1007/s11274-010-

$473 \quad 0572-7$

474 Hardin, J. W., Doerksen, G., Herndon, D., Hobson, M., \& Thomas, F. (1972). Pollination

475 Ecology and Floral Biology of Four Weedy Genera in Southern Oklahoma. The

$476 \quad$ Southwestern Naturalist, 16(3/4), 403. https://doi.org/10.2307/3670071

477 Hayes, R. A., Rebolleda-Gómez, M., Butela, K., Cabo, L. F., Cullen, N., Kaufmann, N., O’Neill,

478 S., \& Ashman, T. L. (2021). Spatially explicit depiction of a floral epiphytic bacterial

479 community reveals role for environmental filtering within petals. MicrobiologyOpen, 10(1).

$480 \quad$ https://doi.org/10.1002/mbo3.1158

481 Igwe, A. N., \& Vannette, R. L. (2019). Bacterial communities differ between plant species and 
482

483

484

485

486

487

488

489

490

491

492

493

494

495

496

497

498

499

500

501

502

503 504 505

soil type, and differentially influence seedling establishment on serpentine soils. Plant and Soil, 441(1-2), 423-437. https://doi.org/10.1007/s11104-019-04135-5

Ikenaga, M., Tabuchi, M., Kawauchi, T., \& Sakai, M. (2016). Application of Locked Nucleic Acid (LNA) Primer and PCR Clamping by LNA Oligonucleotide to Enhance the Amplification of Internal Transcribed Spacer (ITS) Regions in Investigating the Community Structures of Plant-Associated Fungi. Microbes and Environments, 31(3), 339-348. https://doi.org/10.1264/jsme2.ME16085

Imaizumi, T., Kurokawa, S., Ito, M., Auld, B., \& Wang, G. X. (2006). Population structure of Solanum carolinense along the Takano River in Kyoto, Japan as determined by amplified fragment length polymorphism analysis. Weed Research, 46(3), 219-225. https://doi.org/10.1111/j.1365-3180.2006.00499.x

Junker, R. R., Loewel, C., Gross, R., Dötterl, S., Keller, A., \& Blüthgen, N. (2011). Composition of epiphytic bacterial communities differs on petals and leaves. Plant Biology, 13(6), 918924. https://doi.org/10.1111/j.1438-8677.2011.00454.X

Junker, R. R, \& Keller, A. (2015). Microhabitat heterogeneity across leaves and flower organs promotes bacterial diversity. FEMS Microbiology Ecology, 91(9), fiv097. https://doi.org/10.1093/femsec/fiv097

Kido, K., Adachi, R., Hasegawa, M., Yano, K., Hikichi, Y., Takeuchi, S., Atsuchi, T., \& Takikawa, Y. (2008). Internal fruit rot of netted melon caused by Pantoea ananatis (=Erwinia ananas) in Japan. Journal of General Plant Pathology, 74(4), 302-312. https://doi.org/10.1007/s10327-008-0107-3

Kiltz, B. F. 1930. Perennial weeds which spread vegetatively. American Society Agronomy. 22: 216-234.

Knief, C., Ramette, A., Frances, L., Alonso-Blanco, C., \& Vorholt, J. A. (2010). Site and plant 
species are important determinants of the Methylobacterium community composition in the plant phyllosphere. ISME Journal, 4(6), 719-728. https://doi.org/10.1038/ismej.2010.9

Laforest-Lapointe, I., Messier, C., \& Kembel, S. W. (2016). Tree phyllosphere bacterial communities: Exploring the magnitude of intra- and inter-individual variation among host species. PeerJ, 2016(8), e2367. https://doi.org/10.7717/PEERJ.2367

Latif Khan, A., Waqas, M., Kang, S.-M., Al-Harrasi, A., Hussain, J., Al-Rawahi, A., Al-Khiziri, S., Ullah, I., Ali, L., Jung, H.-Y., \& Lee, I.-J. (2014). Bacterial Endophyte Sphingomonas sp. LK11 Produces Gibberellins and IAA and Promotes Tomato Plant Growth. Journal of Microbiology, 52(8), 689-695. https://doi.org/10.1007/s12275-014-4002-7

Lebeis, S. L., Rott, M., Dangl, J. L., \& Schulze-Lefert, P. (2012). Culturing a plant microbiome community at the cross-Rhodes. New Phytologist, 196(2), 341-344.

Levin, S. A. (1992). The Problem of Pattern and Scale in Ecology: The Robert H. MacArthur Award Lecture. Ecology, 73(6), 1943-1967. https://doi.org/10.2307/1941447

Li, Y., Xu, G., Lin, C., Wang, X., \& Piao, C. G. (2018). Aureimonas populi sp. nov., isolated from poplar tree bark. International Journal of Systematic and Evolutionary Microbiology, 68(2), 487-491. https://doi.org/10.1099/ijsem.0.002479

Love, M. I., Huber, W., \& Anders, S. (2014). Moderated estimation of fold change and 524 dispersion for RNA-seq data with DESeq2. Genome Biology, 15(12), 1-21.

Manter, D. K., Delgado, J. A., Holm, D. G., \& Stong, R. A. (2010). Pyrosequencing reveals a highly diverse and cultivar-specific bacterial endophyte community in potato roots. Microbial Ecology, 60(1), 157-166. https://doi.org/10.1007/s00248-010-9658-x 
529 Mcmurdie, P. J., \& Holmes, S. (n.d.). phyloseq: An R Package for Reproducible Interactive

$530 \quad$ Analysis and Graphics of Microbiome Census Data.

$531 \quad$ https://doi.org/10.1371/journal.pone.0061217

532 Milner, S. E., Brunton, N. P., Jones, P. W., O’Brien, N. M., Collins, S. G., \& Maguire, A.R.

533 (2011). Bioactivites of glycoalkaloids and their aglycones from Solanum species. Journal of $534 \quad$ agricultural and food chemistry, 59(8), 3454-3484.

535 Miura, T., Sánchez, R., Castañeda, L. E., Godoy, K., \& Barbosa, O. (2017). Is microbial terroir

536 related to geographic distance between vineyards? Environmental Microbiology Reports,

5379 9(6), 742-749. https://doi.org/10.1111/1758-2229.12589

538 Morrison-Whittle, P., \& Goddard, M. R. (2015). Quantifying the relative roles of selective and

539 neutral processes in defining eukaryotic microbial communities. ISME Journal, 9(9), 2003-

$540 \quad$ 2011. https://doi.org/10.1038/ismej.2015.18

541 Nelson, E. B. (2018). The seed microbiome: Origins, interactions, and impacts. In Plant and Soil

542 (Vol. 422, Issues 1-2, pp. 7-34). Springer International Publishing.

$543 \quad$ https://doi.org/10.1007/s11104-017-3289-7

544 Oksanen, J., Blanchet, F. G., Friendly, M., Kindt, R., Legendre, P., Mcglinn, D., Minchin, P. R.,

545 O’hara, R. B., Simpson, G. L., Solymos, P., Henry, M., Stevens, H., Szoecs, E., \&

546 Maintainer, H. W. (2019). Package “vegan” Title Community Ecology Package Version

$547 \quad 2.5-6$

548 Ottesen, A. R., González Peña, A., White, J. R., Pettengill, J. B., Li, C., Allard, S., Rideout, S.,

549 Allard, M., Hill, T., Evans, P., Strain, E., Musser, S., Knight, R., \& Brown, E. (2013).

550 Baseline survey of the anatomical microbial ecology of an important food plant: Solanum

551 lycopersicum (tomato). BMC Microbiology, 13(1), 114. https://doi.org/10.1186/1471-2180- 
552

553

554

555

556

557

558

559

560

561

562

563

564

565

566

567

568

569

570

571

572

573

574

\section{3-114}

Ottesen, A. R., Gorham, S., Reed, E., Newell, M. J., Ramachandran, P., Canida, T., Allard, M., Evans, P., Brown, E., \& White, J. R. (2016). Using a Control to Better Understand Phyllosphere Microbiota. PLOS ONE, 11(9), e0163482. https://doi.org/10.1371/journal.pone.0163482

Peay, K. G., \& Bruns, T. D. (2014). Spore dispersal of basidiomycete fungi at the landscape scale is driven by stochastic and deterministic processes and generates variability in plantfungal interactions. New Phytologist, 204(1), 180-191. https://doi.org/10.1111/nph.12906

Peay, K. G., Garbelotto, M., \& Bruns, T. D. (2010). Evidence of dispersal limitation in soil microorganisms: Isolation reduces species richness on mycorrhizal tree islands. Ecology, 91(12), 3631-3640. https://doi.org/10.1890/09-2237.1

Qi, S. S., Cnockaert, M., Carlier, A., \& Vandamme, P. (2021). Pedobacter gandavensis sp. nov., pedobacter foliorum sp. nov. and pedobacter planticolens sp. nov., isolated from leaves of arabidopsis thaliana. International Journal of Systematic and Evolutionary Microbiology, 71(3), 004667. https://doi.org/10.1099/ijsem.0.004667

Quast, C., Pruesse, E., Yilmaz, P., Gerken, J., Schweer, T., Yarza, P., Rg Peplies, J., \& Glö Ckner, F. O. (2013). The SILVA ribosomal RNA gene database project: improved data processing and web-based tools. Genome Biology, 15(550). https://doi.org/10.1093/nar/gks1219

Rasmann, S., De Vos, M., Casteel, C. L., Tian, D., Halitschke, R., Sun, J. Y., Agrawal, A. A., Felton, G. W., \& Jander, G. (2012). Herbivory in the Previous Generation Primes Plants for Enhanced Insect Resistance. Plant Physiology, 158(2), 854-863. https://doi.org/10.1104/pp.111.187831 
575 Rebolleda-Gómez, M., Forrester, N. J., Russell, A. L., Wei, N., Fetters, A. M., Stephens, J. D., \&

576 Ashman, T. L. (2019). Gazing into the anthosphere: considering how microbes influence

577 floral evolution. In New Phytologist (Vol. 224, Issue 3, pp. 1012-1020). Blackwell

$578 \quad$ Publishing Ltd. https://doi.org/10.1111/nph.16137

579 Rebolleda-Gómez, M., \& Ashman, T. (2019). Floral organs act as environmental filters and

580 interact with pollinators to structure the yellow monkeyflower (Mimulus guttatus ) floral

581 microbiome. Molecular Ecology, 28(23), 5155-5171. https://doi.org/10.1111/mec.15280

582 Redford, A. J., Bowers, R. M., Knight, R., Linhart, Y., \& Fierer, N. (2010). The ecology of the

583 phyllosphere: Geographic and phylogenetic variability in the distribution of bacteria on tree

584 leaves. Environmental Microbiology, 12(11), 2885-2893. https://doi.org/10.1111/j.1462-

$585 \quad 2920.2010 .02258 . x$

586 Richardson, A. E., Barea, J. M., McNeill, A. M., \& Prigent-Combaret, C. (2009). Acquisition of

587 phosphorus and nitrogen in the rhizosphere and plant growth promotion by microorganisms.

588 In Plant and Soil (Vol. 321, Issues 1-2, pp. 305-339). Springer.

589 https://doi.org/10.1007/s11104-009-9895-2

590 Russell, A. L., Rebolleda-Gómez, M., Shaible, T. M., \& Ashman, T. (2019). Movers and

591 shakers: Bumble bee foraging behavior shapes the dispersal of microbes among and within

592 flowers. Ecosphere, 10(5), e02714. https://doi.org/10.1002/ecs2.2714

593 Sakai, M., \& Ikenaga, M. (2013). Application of peptide nucleic acid (PNA)-PCR clamping

594 technique to investigate the community structures of rhizobacteria associated with plant

595 roots. Journal of Microbiological Methods, 92(3), 281-288.

596 https://doi.org/10.1016/j.mimet.2012.09.036

597 Selosse, M. A., Baudoin, E., \& Vandenkoornhuyse, P. (2004). Symbiotic microorganisms, a key 
598 for ecological success and protection of plants. Comptes Rendus - Biologies, 327(7), 639599 648. https://doi.org/10.1016/j.crvi.2003.12.008

600 Shade, A., McManus, P. S., \& Handelsman, J. (2013). Unexpected diversity during community 601 succession in the apple flower microbiome. MBio, 4(2).

602 https://doi.org/10.1128/mBio.00602-12

603 Smets, W., Wuyts, K., Oerlemans, E., Wuyts, S., Denys, S., Samson, R., \& Lebeer, S. (2016).

604 Impact of urban land use on the bacterial phyllosphere of ivy (Hedera sp.). Atmospheric 605 Environment, 147, 376-383. https://doi.org/10.1016/j.atmosenv.2016.10.017

606 Stone, B. W. G., \& Jackson, C. R. (2016). Biogeographic Patterns Between Bacterial 607 Phyllosphere Communities of the Southern Magnolia (Magnolia grandiflora) in a Small 608 Forest. Microbial Ecology, 71(4), 954-961. https://doi.org/10.1007/s00248-016-0738-4 609 Stone, B. W. G., Weingarten, E. A., \& Jackson, C. R. (2018). The Role of the Phyllosphere 610 Microbiome in Plant Health and Function. In Annual Plant Reviews online (pp. 533-556). 611 Wiley. https://doi.org/10.1002/9781119312994.apr0614

612 Storey, S., Ashaari, M. M., Clipson, N., Doyle, E., \& de Menezes, A. B. (2018). Opportunistic 613 Bacteria Dominate the Soil Microbiome Response to Phenanthrene in a Microcosm-Based 614 Study. Frontiers in Microbiology, 9(NOV), 2815. https://doi.org/10.3389/fmicb.2018.02815

615 Taylor, M. W., Tsai, P., Anfang, N., Ross, H. A., \& Goddard, M. R. (2014). Pyrosequencing 616 reveals regional differences in fruit-associated fungal communities. Environmental 617 Microbiology, 16(9), 2848-2858. https://doi.org/10.1111/1462-2920.12456

618 Tewksbury, J. J., Levey, D. J., Huizinga, M., Haak, D. C., \& Traveset, A. (2008). Costs and 619 benefits of capsaicin-mediated control of gut retention in dispersers of wild chilies. Ecology, $620 \quad 89(1), 107-117$. https://doi.org/10.1890/07-0445.1 
621 Tewksbury, J. J., Reagan, K. M., Machnicki, N. J., Carlo, T. A., Haak, D. C., Peñaloza, A. L. C.,

622 \& Levey, D. J. (2008). Evolutionary ecology of pungency in wild chilies. Proceedings of

623 the National Academy of Sciences of the United States of America, 105(33), 11808-11811.

624 https://doi.org/10.1073/pnas.0802691105

625 Ushio, M., Yamasaki, E., Takasu, H., Nagano, A. J., Fujinaga, S., Honjo, M. N., Ikemoto, M.,

626 Sakai, S., \& Kudoh, H. (2015). Microbial communities on flower surfaces act as signatures

627 of pollinator visitation. Scientific Reports, 5. https://doi.org/10.1038/srep08695

628 Wei, N., \& Ashman, T. L. (2018). The effects of host species and sexual dimorphism differ

629 among root, leaf and flower microbiomes of wild strawberries in situ. Scientific Reports,

$630 \quad 8(1), 5195$. https://doi.org/10.1038/s41598-018-23518-9

631 Wickham, M. H. (2015). Package "ggplot2” Type Package Title An implementation of the 632 Grammar of Graphics.

633 Willis, A. D. (2019). Rarefaction, Alpha Diversity, and Statistics. Frontiers in Microbiology, 634 10(OCT), 2407. https://doi.org/10.3389/fmicb.2019.02407

635 Yu, Z., Ikenaga, M., Zhen-Hua, Y. U., Jiang, Y. U., Sakai, M., Liu, X.-B., \& Wang, G.-H.

636 (2016). Characterization of root-associated bacterial community structures in soybean and

637 corn using locked nucleic acid (LNA) oligonucleotide-PCR clamping and 454

638 pyrosequencing View project Characterization of root-associated bacterial community

639 structures in soybean and corn using locked nucleic acid (LNA) oligonucleotide-PCR

640 clamping and 454 pyrosequencing. 15(8), 1883-1891. https://doi.org/10.1016/S2095-

$641 \quad 3119(15) 61195-9$

642 Zemenick, A. T., Vannette, R. L., \& Rosenheim, J. A. (2021). Linked networks reveal dual roles

643 of insect dispersal and species sorting for bacterial communities in flowers. In bioRxiv (p. 
644 847376). bioRxiv. https://doi.org/10.1101/847376

645 Zheng, Y., \& Gong, X. (2019). Niche differentiation rather than biogeography shapes the

646 diversity and composition of microbiome of Cycas panzhihuaensis. Microbiome, 7(1), 152.

647 https://doi.org/10.1186/s40168-019-0770-y 


\section{Figure 1}

Sampling locations and number of plants collected from each location.

Sampling locations in Blacksburg, VA. Blue circles indicate Solanum carolinense locations sampled. Map on the lower left corner shows the sampling location, indicated in blue, in relation to the eastern United States. Map was created using Google Earth. 


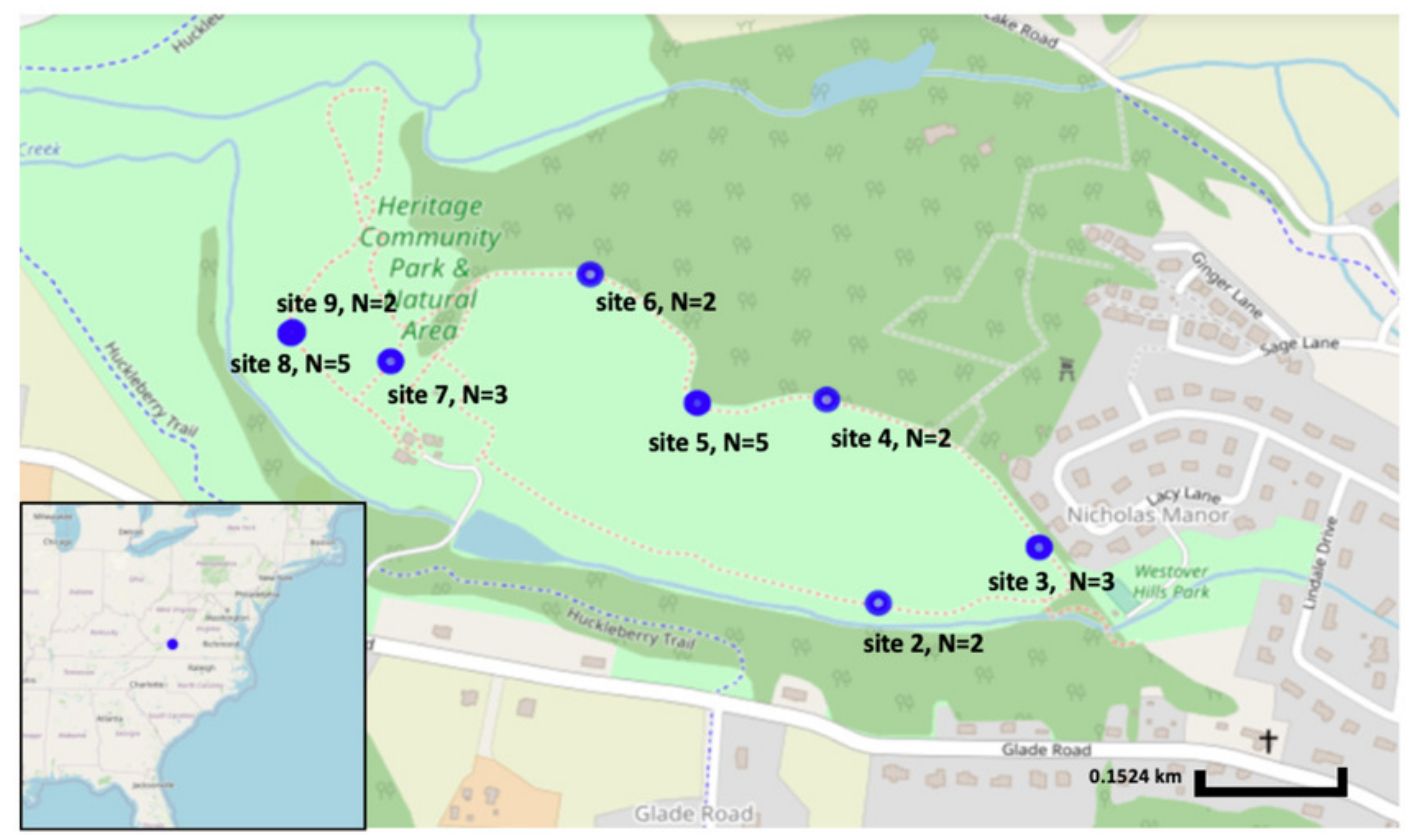


Figure 2

Relative abundance of microbial communities by sampling location.

Relative abundance of bacterial orders that constituted $>2 \%$ of $\mathrm{S}$. carolinense fruit microbiome, by sample location. 


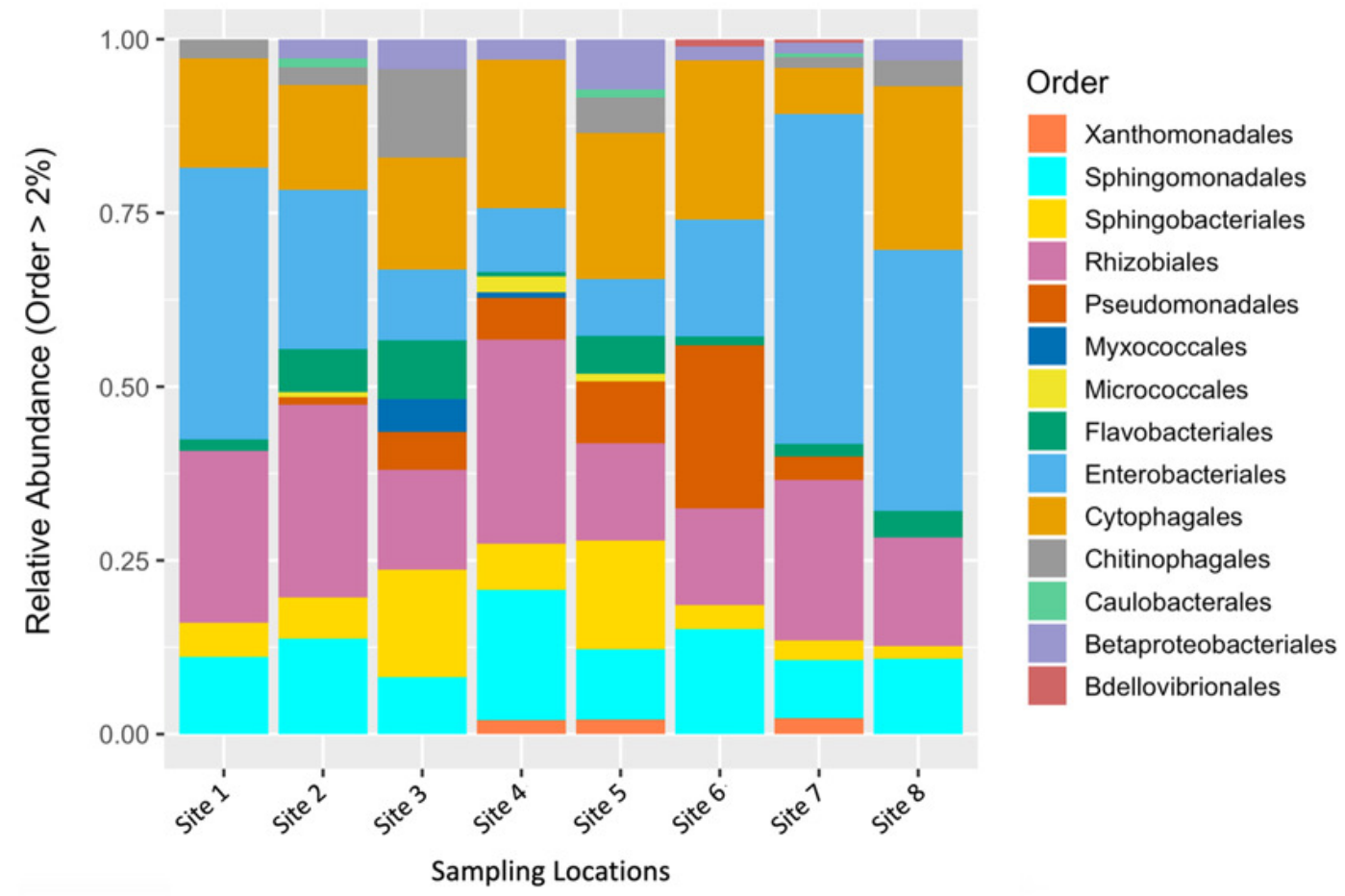


Figure 3

Alpha diversity of microbial communities associated with S. carolinense fruit sample locations.

Observed Richness, Shannon, and Faith's phylogenetic diversity by sampling locations. 

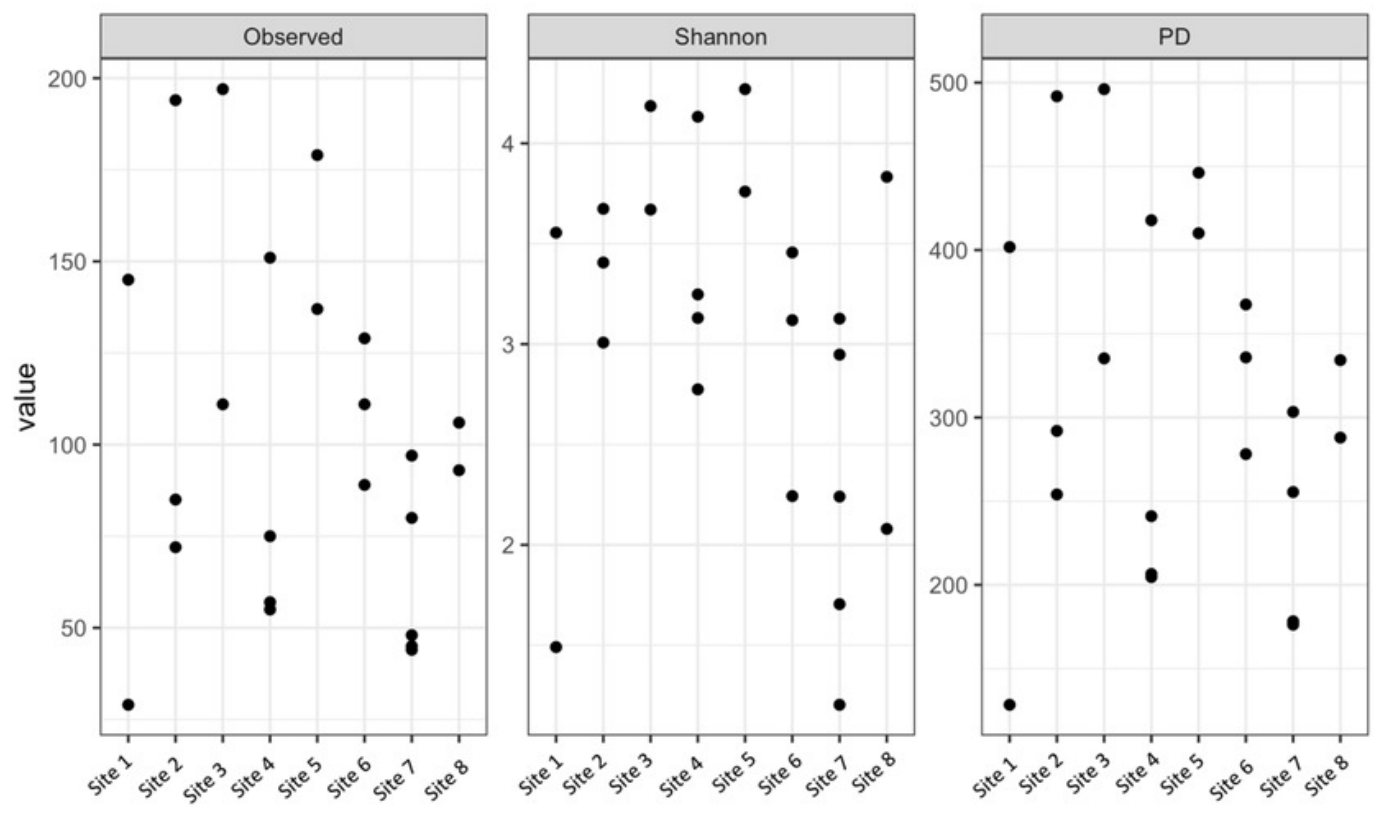

Sampling Locations 


\section{Figure 4}

Beta diversity (Bray-Curtis) of sample locations.

PCoA results illustrating distances among microbial communities associated with $\mathrm{S}$.

carolinense fruit, colored by sample locations (Bray-Curtis, PERMANOVA, $p=0.711, \mathrm{DF}=22$,

$R^{2}=0.3033$ ). The axes indicate the percentage of variation in the data with axis 1 (the first

component) representing $18.3 \%$ of the variation and axis 2 (the second component)

representing $10.8 \%$ of the variation. 


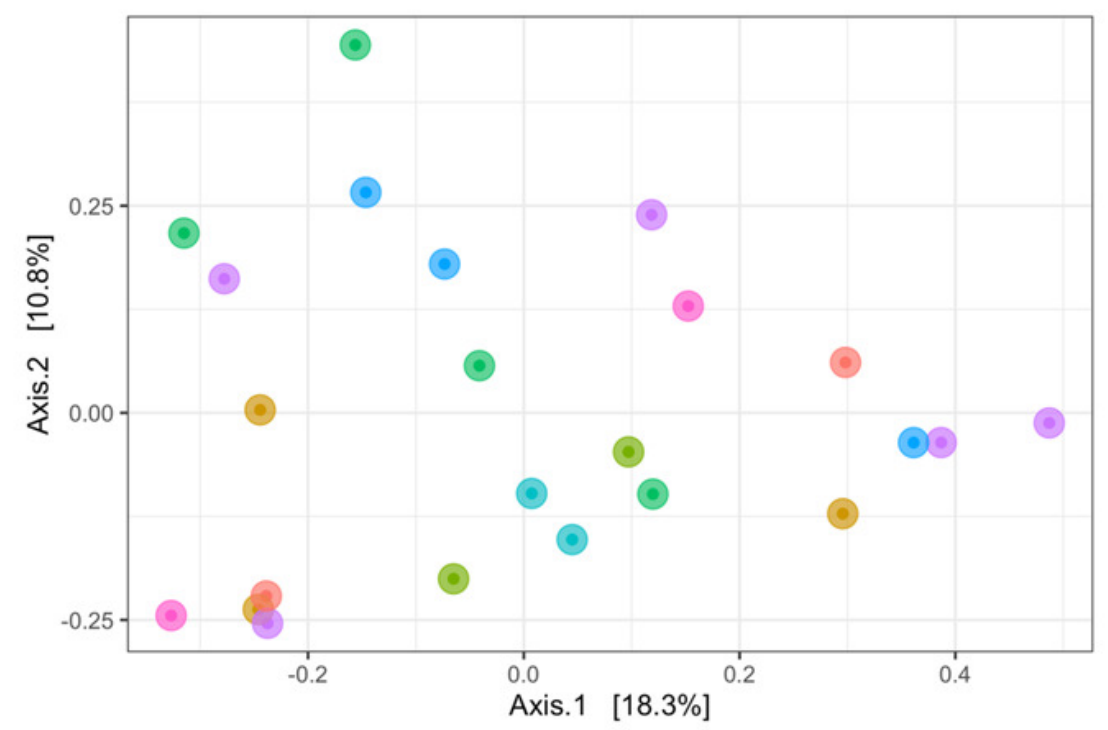

\section{Sample Locations}

(-) Site 1

(-) Site 2

(-) Site 3

(-) Site 4

(-) Site 5

(-) Site 6

(-) Site 7

(-) Site 8 
Figure 5

Mantel Test.

No observable relationship between Bray-Curtis Dissimilarly and spatial distance (geographic distance Euclidean) was detected between bacterial diversity and distance ( $r: 0.03343, p=$ $0.302)$. 


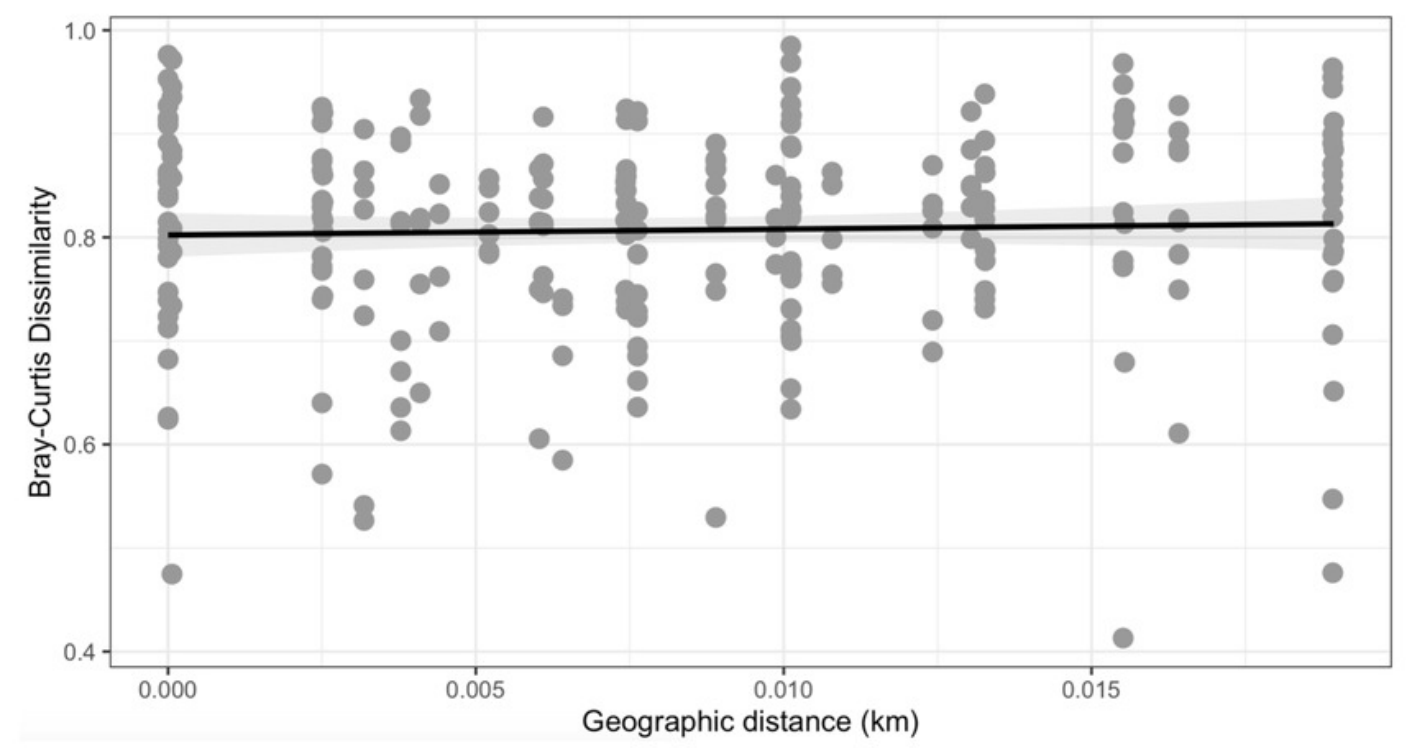


Figure 6

Core microbial communities.

Microbial genera that were present (prevalence) in at least $60 \%$ of the samples at a relative abundance of at least $0.10 \%$. 


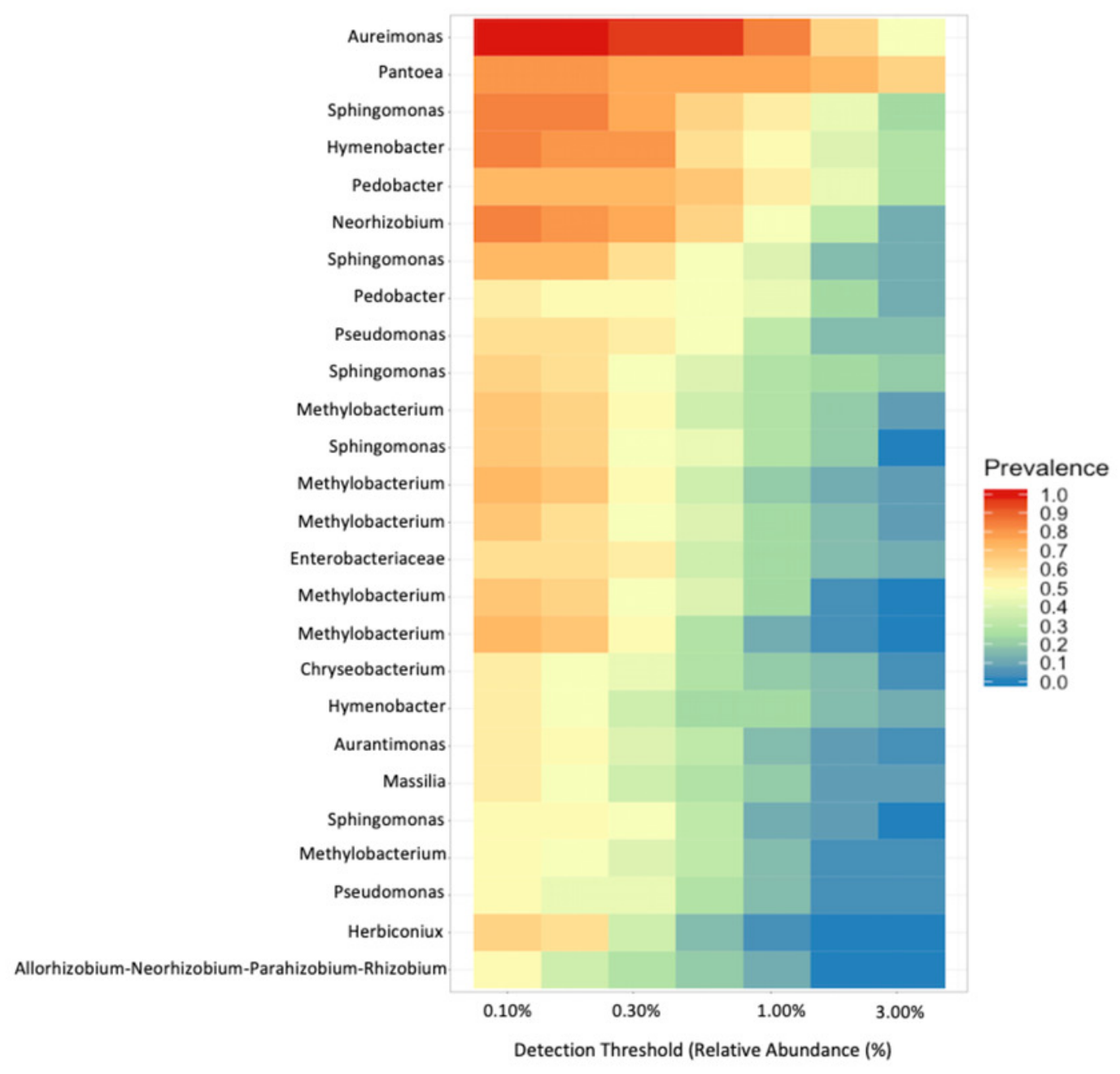

